\title{
Design of RF Energy Harvesting Antenna using Optimization Techniques
}

\author{
Mr. S. Vijay Gokul \\ Assistant Professor, \\ Dept of Electronics and Communication Engg, \\ Mepco Schlenk Engineering College, Sivakasi, \\ Tamilnadu, India.
}

\author{
Ms. M. Suba Lakshmi , Ms. T. Swetha \\ Dept of Electronics and Communication Engg, \\ Mepco Schlenk Engineering College, Sivakasi, \\ Tamilnadu, India.
}

\begin{abstract}
This paper deals with the design, analysis and Optimization of Radio Frequency (RF) energy harvesting antenna for Wireless Local Area Network (WLAN) sources .The designed antenna is simulated using ANSYS HFSS(High Frequency Structure Simulator) and FR4 epoxy material as a substrate with a dielectric constant of 4.4 with a loss tangent of 0.02 . It is a rectangular microstrip patch antenna with H\&E slots and consists of a radiating element with $50 \mathrm{ohm}$ microstrip inset feed. Moreover, the combined configuration of proposed antenna with $H \& E$ shaped slots in design provides maximum efficiency.More simulation iterations are performed in order to maximize the Gain of ISM band operating at a frequency of $2.45 \mathrm{GHz}$ which provides a return loss of -24.77 dB, Voltage Standing Wave Ratio (VSWR) of 1.07 and Gain of $6.58 \mathrm{~dB}$.The optimization of the antenna is carried out by employing Genetic Algorithm (GA). Antenna optimization and gain enhancement by applying genetic algorithm is implemented with the help of MATLAB and ANSYS Optimetrics tool. After applying optimization algorithm the performance of the antenna has been improved with a Gain of $7 \mathrm{~dB}$. The design methodology of microstrip patch antenna and optimizations are presented.
\end{abstract}

Keywords: Microstrip patch antenna; ISM band; RF energy harvesting; Genetic Algorithm (GA); Gain and Return loss.

\section{INTRODUCTION}

The energy harvesting is the method through which energy is derived from external sources like: solar power, thermal energy, wind energy and kinetic energy (eg: ambient energy) which are captured and fed to small electronic wireless operating devices like wireless sensor networks etc., [1]. Lot of RF energy gets wasted due to non reception of the device. In order to make use of renewable energy resources (Radio Frequency) to drive low power appliances and make it battery free RF energy harvesting antenna is mainly used. This enhances the usability and reliability of the device [2]. The idea of energy harvesting is not innovative rather it came hundred years ago. The method of energy harvesting is to extract energy from the environment in order to produce electricity is called energy harvesting or energy scavenging [3]. Usually the energy harvesters will not provide sufficient amount of power for feeding electronic devices, the reason for this is mainly because there are no such technologies have developed in order to extract more and more RF energy. But this technology can provide enough amount amount of energy sufficient of operating low power devicesin order to operate them separately [4].However it is observed that a standard microstrip patch antennas should possess very narrow operating bandwidth. Many procedures have been introduced to solve this problem to some extent they are listed as: use a substrate of high dielectric permittivity [5], use of defected ground structures at the ground plane [6], use of metamaterials at the ground plane [7] and addition of slots on the patches [8] and use of patches with $\mathrm{H} \& \mathrm{E}$ Shape instead of other shapes and optimization of patch shapes and gain by introducing one of the optimization algorithms like genetic algorithm for better antenna performance. These challenges are efficient in order to attain broader bandwidth and to achieve more gain and directivity for energy harvesting application [9-12]. In this paper RF energy is harvested using microstrip patch antenna and the performance is improved by applying genetic algorithm optimization technique [GA].

\section{ANTENNA DESIGN}

Microstrip patch antennas are more popular because of low cost and ease of fabrication. Microstrip patch antenna consists of dielectric material, radiating element and the ground plane. The rectangular shape is widely considered to realize the microstrip antenna. The simulation tool used for antenna design is High Frequency Structure Simulator version 2017(HFSS 17.2). The simple microstrip patch antenna is designed using the substrate FR4_epoxy because of its low cost and ease of fabrication. It has the dielectric constant value of 4.4 and the loss tangent is 0.02 and the resonating frequency is $2.45 \mathrm{GHz}$. The detailed parameters are given in the Table 1 . The formulae to determine the patch dimensions are as follows:

$$
\begin{aligned}
& W=\frac{\lambda_{0}}{2}\left(\frac{2}{\varepsilon_{r}+1}\right)^{\frac{1}{2}} \\
& L=\frac{1}{2 f_{r} \sqrt{\varepsilon_{e f f}} \sqrt{\mu_{0}} \varepsilon_{0}}-2 \Delta L
\end{aligned}
$$

Using the above equations (1) and (2) we have calculated the width and length of the patch. 
From the above equations, $\varepsilon_{\text {eff }}, \mu_{0}$ and $\Delta L$ are the effective dielectric constant, permeability of free space and the extension length respectively. The effective dielectric constant $\varepsilon_{\text {eff }}$ and the extension length $\Delta L$ can be computed through the following equations respectively as.

$\varepsilon_{\text {eff }}=\frac{\varepsilon_{r}+1}{2}+\frac{\varepsilon_{r}-1}{2}\left[\left(1+\frac{12 W}{h}\right)\right]^{\frac{-1}{2}}$

$\Delta L=0.412 h\left[\left(\frac{\varepsilon_{\text {eff }}+0.3}{\varepsilon_{\text {eff }}-0.258}\right)\left(\frac{\frac{W}{h}+0.264}{\frac{W}{h}+0.813}\right)\right]$

The proposed microstrip patch antenna is designed with an

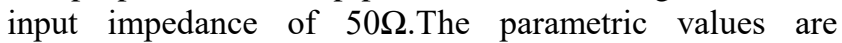
calculated from the given specific equations and the values are mentioned in the given Table 1. With those calculated numerical values the simple microstrip patch antenna with $\mathrm{H} \& \mathrm{E}$ shaped slots are designed as shown in the Figure 1. For an antenna to radiate, it should attain a return loss of more than $-10 \mathrm{~dB}$. In order to further improve the return loss for better performance two slots are introduced on the patch. Thus in this proposed design H\&E shaped slots are introduced in the antenna. Here two patches are introduced (i.e. Patch 1 and Patch 2). Patch 1 is fed by microstrip inset feed and due to mutual conductance the feed is automatically fed to Patch 2 through Patch 1.This enhances the better performance of the antenna with improved return loss and vswr values. In order to improve the gain and directivity, defected ground structures (DGS) i.e., metamaterials are introduced on the ground in antenna design. This improves the gain, directivity and overall efficiency of the antenna. The design specifications are mentioned in the below Table 1 .

Table 1: Design Specifications for Energy Harvesting Antenna

\begin{tabular}{|c|l|l|}
\hline S.no & \multicolumn{1}{|c|}{ Parameters } & Values \\
& \multicolumn{1}{|c|}{ Operating Frequency } \\
1 & Substrate dielectric constant & $2.45 \mathrm{GHz}$ \\
2 & Substrate Thickness & 4.4 \\
3 & Substrate Width & $1.575 \mathrm{~mm}$ \\
4 & Substrate Length & $53 \mathrm{~mm}$ \\
5 & Patch 1 Width & $49 \mathrm{~mm}$ \\
6 & Patch 1 Length & $31 \mathrm{~mm}$ \\
7 & Patch 2 Width & $28 \mathrm{~mm}$ \\
8 & Patch 2 Length & $1 \mathrm{~mm}$ \\
9 & Feed Width & $4.9 \mathrm{~mm}$ \\
10 & Feed Length & $17.5 \mathrm{~mm}$ \\
11 & Input Impedance & $50 \Omega$ \\
12 & &
\end{tabular}

\section{SIMULATION RESULTS AND DISCUSSION}

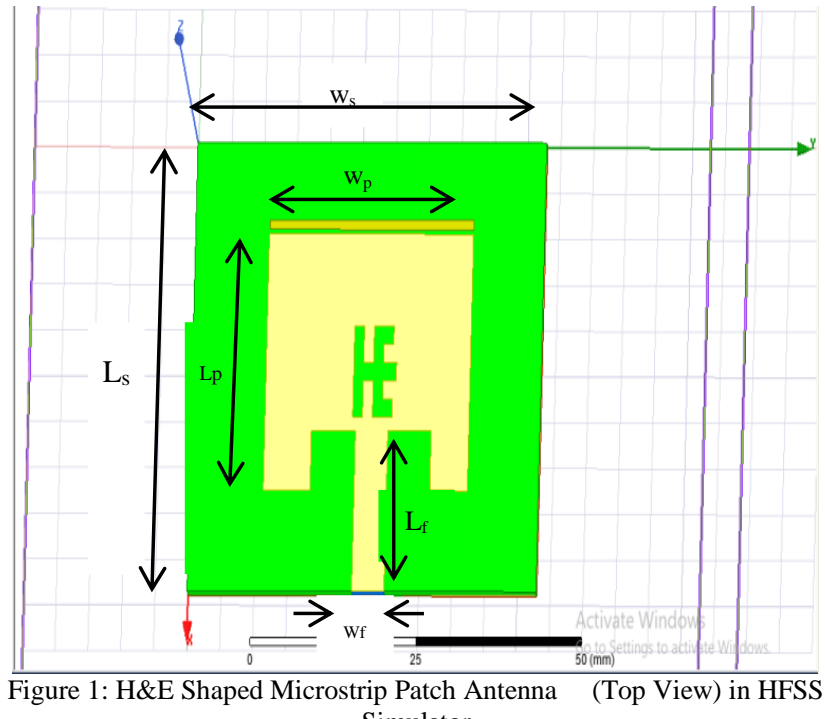

Simulator

Where, Ls, Ws = Length and Width of the substrate $\mathrm{Lp}, \mathrm{Wp}=$ Length and Width of the patch $\mathrm{L}_{\mathrm{f}}, \mathrm{W}_{\mathrm{f}}=$ Length and Width of the feed

\section{A. DEFECTEDGROUNDSTRUCTURES}

Defected ground structure (i.e., metamaterials) is introduced in the ground in order to improve the gain, directivity and overall efficiency of the antenna for better performance of the antenna in energy harvesting capability which was shown in Figure 2.

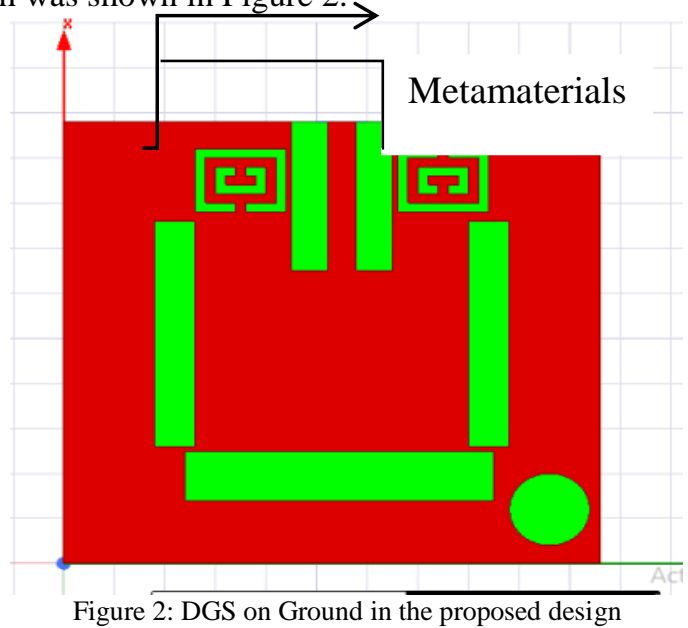

\section{B. SIMULATION RESULTS}

\section{(a) Return loss}

The simulated return loss $\left(S_{11}\right)$ parameterfor the given microstrip patch antenna before optimization is $\quad-\mathbf{2 9 . 2 5} \mathrm{dB}$ which is shown in the Figure 3. 


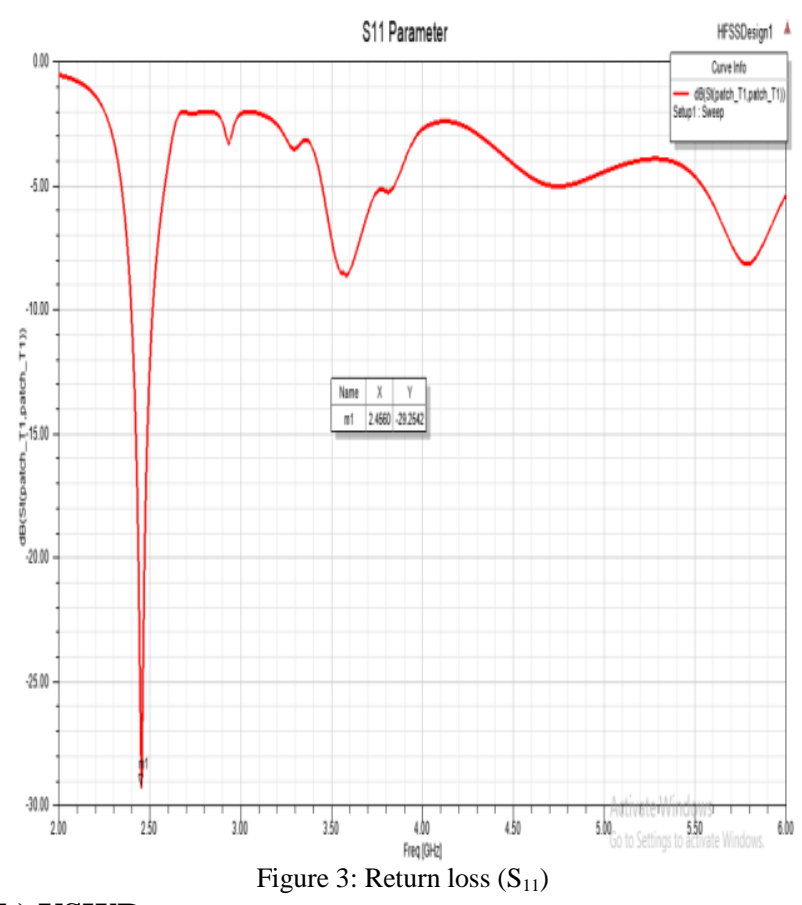

(b) VSWR

The Voltage Standing Wave Ratio (VSWR) obtained before optimization from the given design is 1.07 which is shown in the Figure 4.

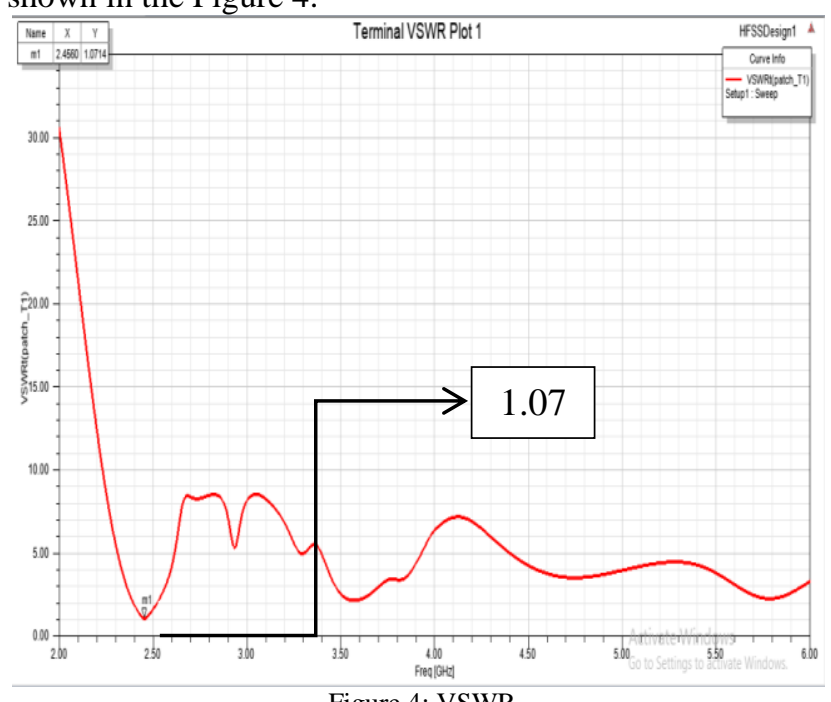

(c) Radiation Pattern

The radiation pattern obtained in this designed antenna is omnidirectional, whis is shown in the Figure 5.

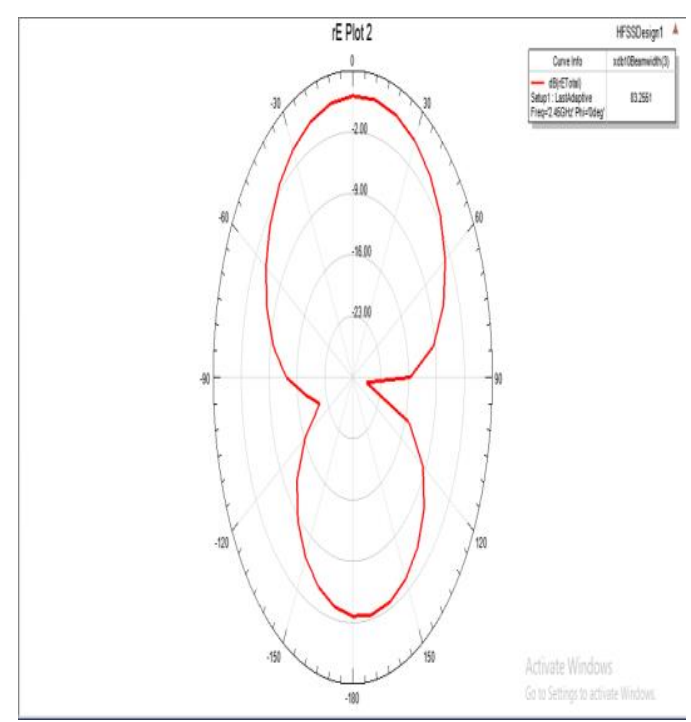

Figure 5. Radiation Pattern

\section{(d) Gain}

The observed Gain for given H\&E shaped microstrip patch antenna before optimization is $5 \mathrm{~dB}$ which is given in the below Figure 6.

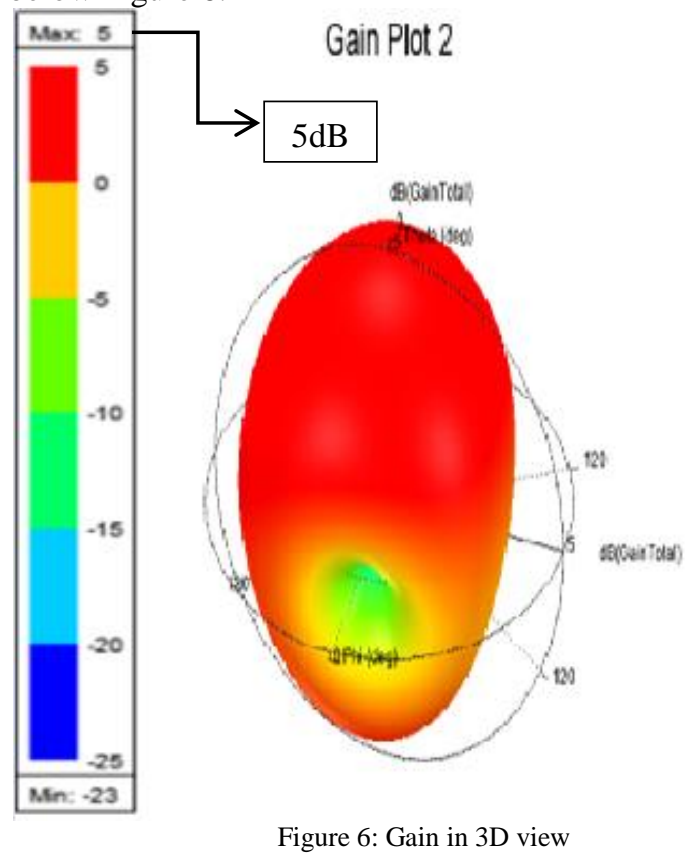

(e) Directivity

The observed Directivity for the given microstrip patch antenna before optimization is $6 \mathrm{~dB}$ which is shown in the Figure 7. 


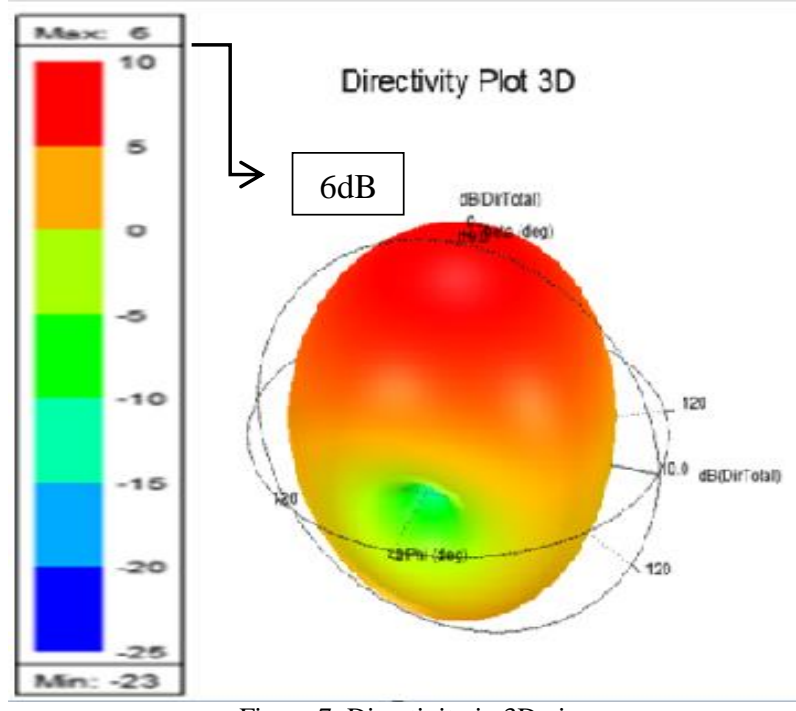

Figure 7: Directivity in 3D view

\section{(f) Current Distribution}

The observed current distribution of simulated H\&E shaped microstrip patch antenna before optimization is shown in the Figure 8.

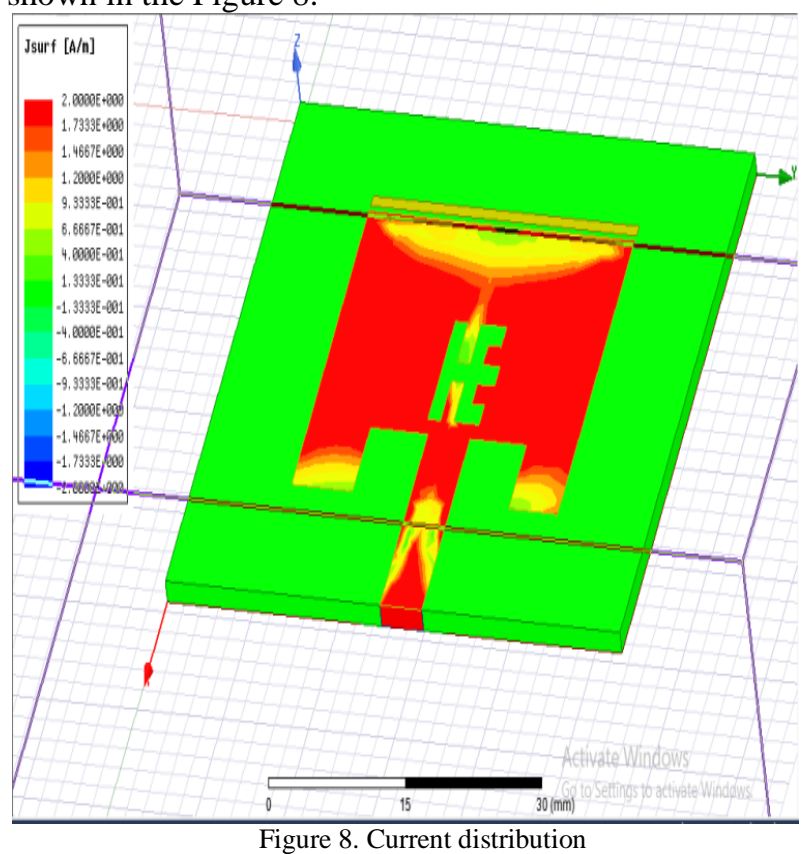

\section{GENETIC ALGORITHM}

Genetic Algorithm (GA) is one of the powerful optimization techniques used in the wide area of electromagnetics.It is different from other optimization techniques. Holland and De Jong introduced the hypothesis. It contains the optimization search aproaches and concepts besed on natural selection and evolution. The functional block diagram of GA is represented in the Figure 9.

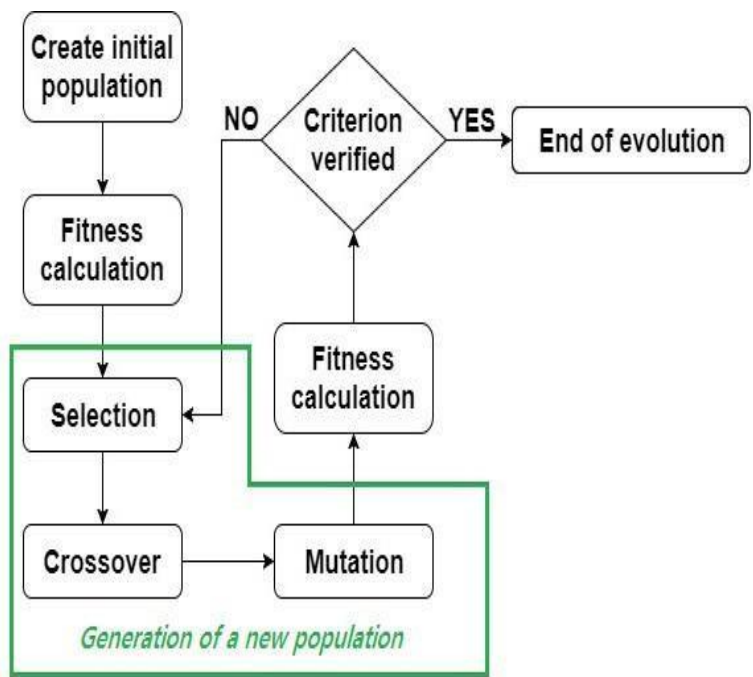

Figure 9. Functional Block Diagram of Genetic Algorithm

Initially Genetic Algorithm is performed by creation of initial population. Each individuals in the populations are coded as string of bits they are represented as chromosomes. They are created randomly. The fitness of each individual is determined by the cost function or objective function. A good chromosome is always determined by the best value of the objective function. The objective function is used to calculate the fitness of these individuals.By mating these individuals new generation will be formed. The individuals who have higher fitness values are chosen for reproduction. Crossover and mutations are generally used for global search of the objective function or the cost function. The best individuals will be obtained in the next generation without any change. This process will be repeated continuously untill end of the evolution is reached.In this paper,Genetic Algorithm is used for has been used to enhance the performance of microstrip patch antenna (MPA) by obtaining high gain and directivity and reduced size at the given resonating frequency by optimizing the substrate dimensions and patch dimensions. The antenna design is simulated in Ansys HFSS 2017 software and the genetic algorithm optimization is done through MATLAB software. The resultant results from the MATLAB simulation is taken and applied in the HFSS environment to perform further simulations.

\section{A.GENETIC ALGORITHMIMPLEMENTATION}

The Optimization steps for obtaining the best results using GA in MATLAB are summarized as below:

Step 1:Study the parameters that need to be optimized using GA from HFSS antenna design.

Step 2:Design the variable behavior for mapping.

Step 3: Formulate the constraints in Matlab.

Step 4:Model the objective function equation and Genetic algorithm program for the design parameters.

Step 5:Setup the bound values ( i.e, Upper and lower limits ) for the desired parameters.

Step 6: Run optimization process and Analyse the results.

Step 7: Select the best optimal antenna design values 
Step 8:Apply thebest values which are obtained from the MATLAB in HFSS antenna design.

Step 9:Run and Analyse the results.

Table 2: GA Parameters Used for Antenna Design

\begin{tabular}{|c|c|}
\hline GA Parameters & Values \\
\hline Population Size & 10 \\
Population Type & Bit String \\
Crossover Fraction & 0.2 \\
Crossover & Single Point Crossover \\
Mutation & 0.01 \\
Total No of Iterations & 5000 \\
\end{tabular}

\section{B. RESULTANT MICROSTRIP PATCH (AFTER OPTIMIZATION)}

ANTENNA

The resultant microstrip $\mathrm{H} \& \mathrm{E}$ shaped patch antenna after optimization using genetic algorithm for energy harvesting is shown in the Figure 10 and 11.

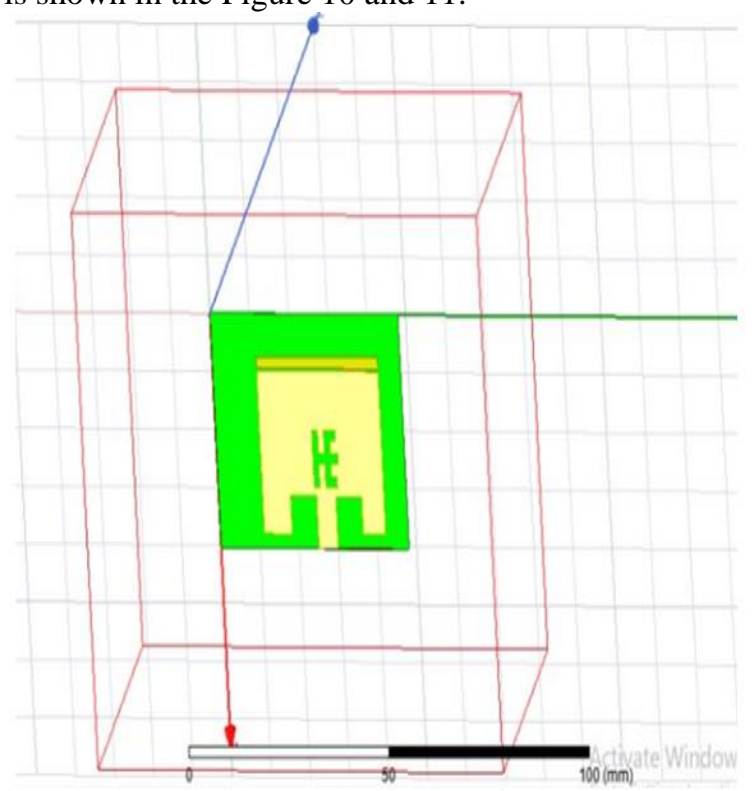

Figure 10 : ProposedMPA in Top View

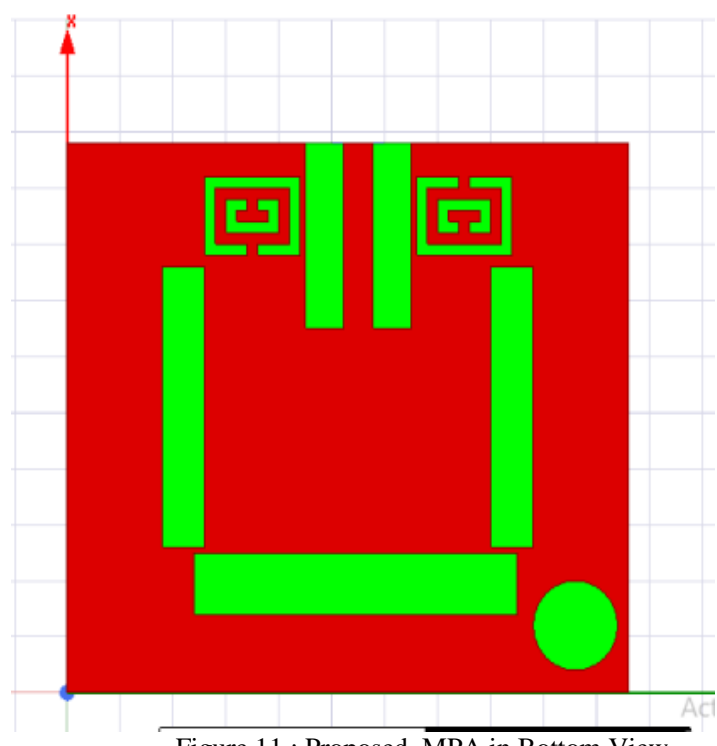

Figure 11 : Proposed $\overline{\text { MPA in Bottom View }}$

C. PROPOSED ANTENNA SPECIFICATIONS

Table 3 : Design Specifications After Optimization

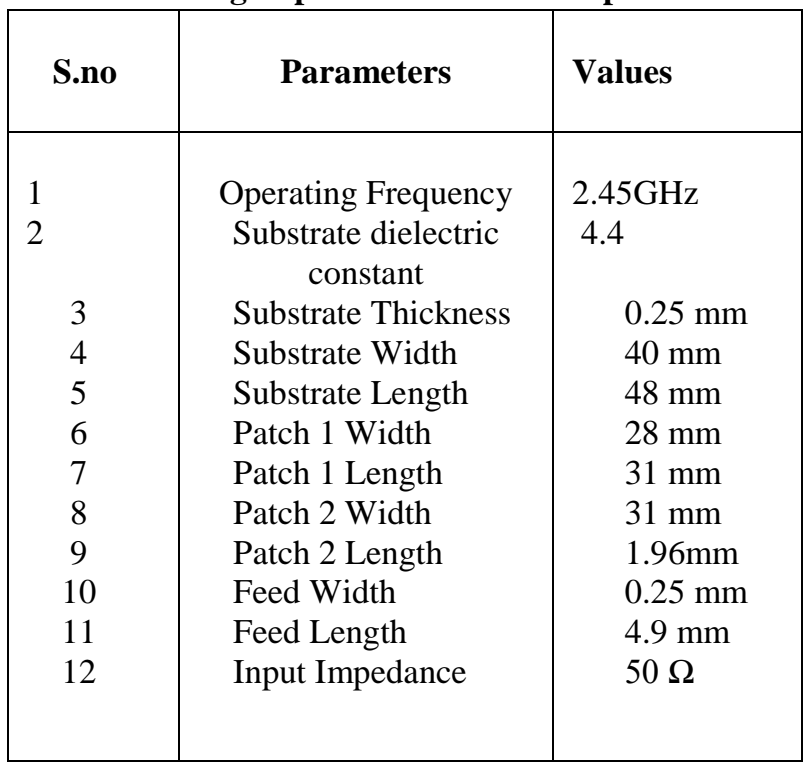

\section{RESULTS AND DISCUSSIONS (AFTER OPTIMIZATION)}

(a) Return loss

The simulated results for the given microstrip $\mathrm{H} \& \mathrm{E}$ shaped microstrip patch antenna after optimization is - 
$24.77 \mathrm{~dB}$ which is shown in the Figure 12.

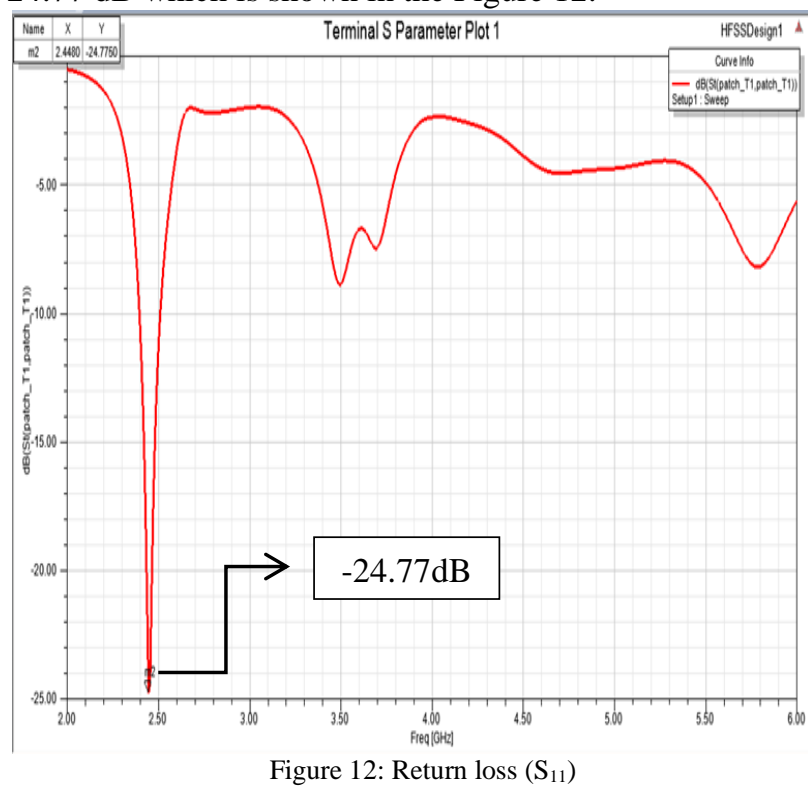

(b) VSWR

The Voltage Standing Wave Ratio (VSWR) obtained after optimization from the given design is 1.12 which is shown in the Figure 13.

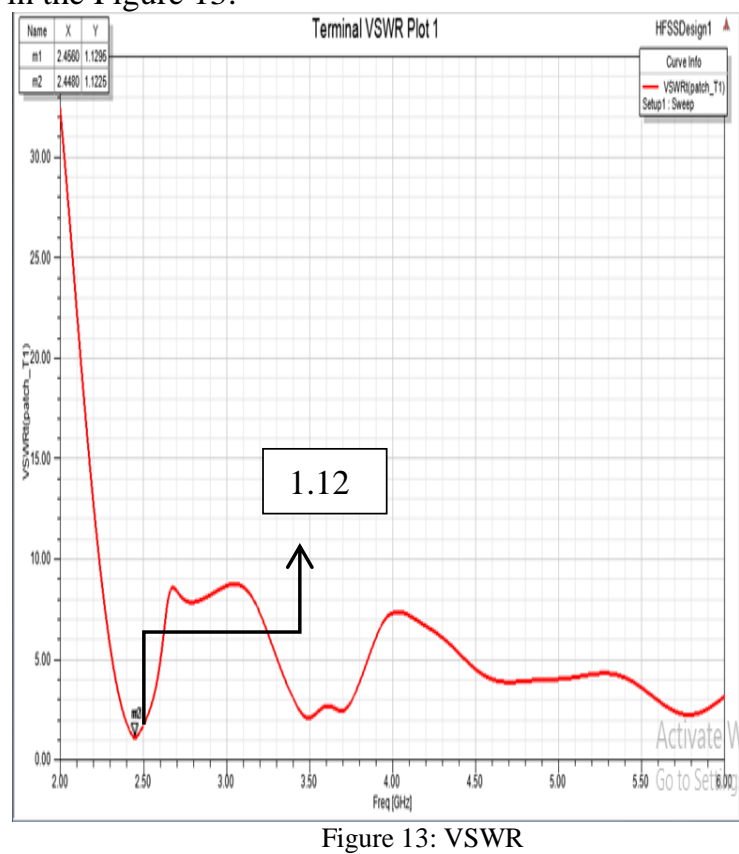

(c) Gain

The observed Gain for given H\&E shaped microstrip patch antenna after optimization is $6.58 \mathrm{~dB}$ which is given in the below Figure 14.

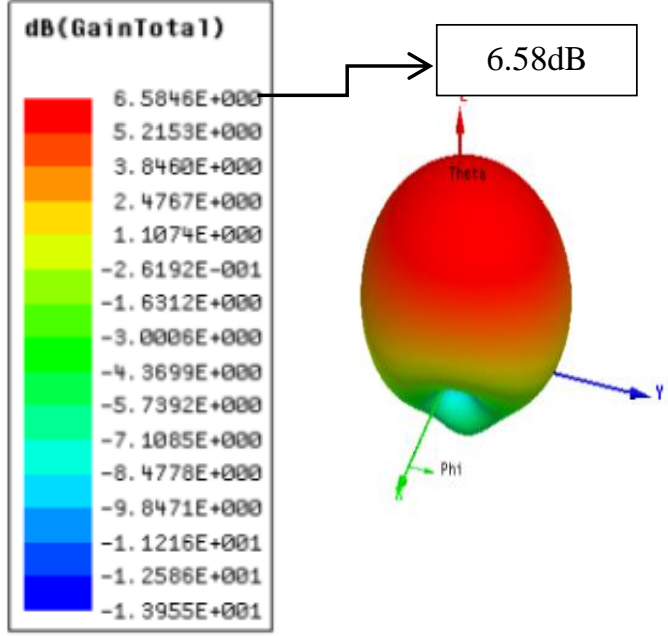

(d) Directivity

Figure 14: Gain in 3D view

The observed Directivity for the given microstrip patch antenna after optimization is $7.0 \mathrm{~dB}$ which is shown in the Figure 15.

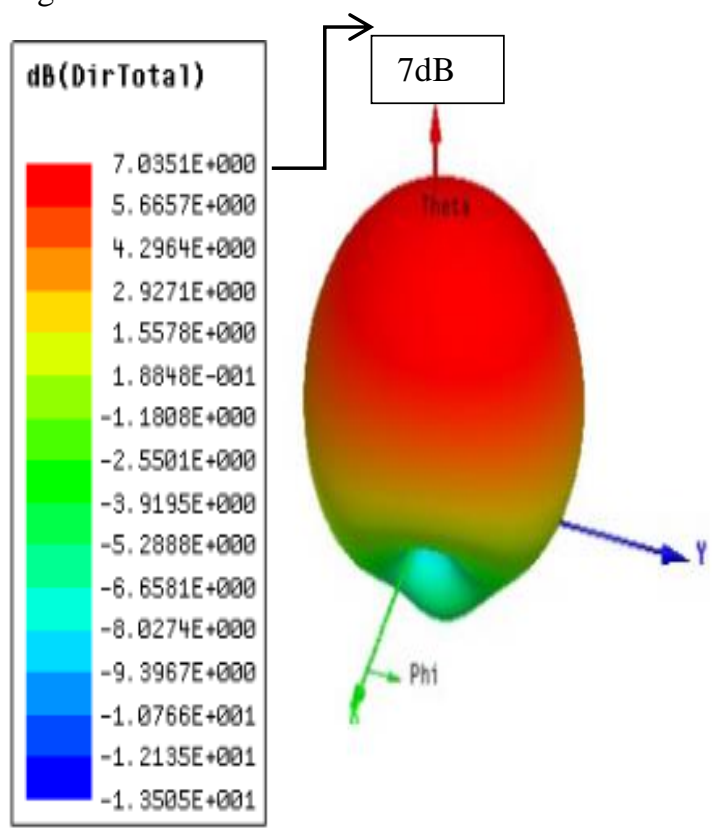

Figure 15: Directivity in 3D view

Table 4: Comparison between the Proposed RF Energy Harvesting Antenna (Before \& After Optimization)

\begin{tabular}{|c|c|c|c|c|}
\hline Parameters & Gain & Directivity & Returnloss & VSWR \\
\hline $\begin{array}{c}\text { H \& E Shaped } \\
\text { Microstrip } \\
\text { Patch Antenna } \\
\text { ( Before } \\
\text { Optimization ) }\end{array}$ & $5 \mathrm{~dB}$ & $6 \mathrm{~dB}$ & $-29.25 \mathrm{~dB}$ & 1.07 \\
\hline $\begin{array}{c}\text { H \& E Shaped } \\
\text { Microstrip } \\
\text { Patch Antenna } \\
\text { ( After } \\
\text { Optimization ) }\end{array}$ & $6.5 \mathrm{~dB}$ & $7 \mathrm{~dB}$ & $-24.77 \mathrm{~dB}$ & 1.12 \\
\hline
\end{tabular}




\section{CONCLUSION}

Thus $\mathrm{H} \& \mathrm{E}$ shaped microstrip patch antenna for energy harvesting in one of the well known simulators known as Ansys High Frequency Structure Simulator (HFSS) and the results will be further improved by using one of the optimization techniques i.e., Genetic Algorithm (GA) in well known software called MATLAB 2019a and then the optimized results will be fed into HFSS inorder to obtain the high gain and antenna efficiency. The simulation results shows that the antenna will radiate at $2.45 \mathrm{GHz}$ frequency which will be included under ISM band operating range. The aim of this work is to improve gain of the antenna inorder to improve the antenna performance for RF energy harvesting capability.This proposed design exhibits high gain of $6.5 \mathrm{~dB}$ with a return loss of $-24.77 \mathrm{~dB}$ and vswr of 1.12 and directivity of $7 \mathrm{~dB}$. The efficiency of the proposed design is reached upto $95 \%$ and thus the it can provide far field radiation and makes the antenna size as much more compact for easy handling capability. Hence the antenna can be used as the front end section of the energy harvesting system. Therefore the antenna can be suitable for RF energy harvesting applications.Finally it is concluded that the proposed energy harvesting antenna can be used for providing power on demand for short range sensing applications.

\section{VI . REFERENCES}

[1] Muhammad Salman Iqbal, Tariq Jameel Khanzada,Faisal A. Dahri, Asif Ali, Mukhtiar Ali, Abdul Wahab Khokhar, "Analysis and Maximizing Energy Harvesting from RF Signals using TShaped Micro strip Patch Antenna", (IJACSA) International Journal of Advanced Computer Science and Applications, Vol. 10, No. 1, 2019

[2] Kayhan Çelik, Erol Kurt, "A novel meander line integrated Eshaped rectenna for energy harvesting applications", Int J RF Microwave Computer Aided Eng.2019

[3] Jaget Singh,B.S. Sohi, Kanav Badhan,"Slit loaded H- Shaped Microstrip Patch Antenna for $2.4 \mathrm{GHz}$ ", Int Journal of Applied Engineering Research ISSN 0973-4562 Volume13, Number 18 (2018)

[4] Bilal S. Taha , Hamzah M. Marhoon , Ahmed A.Naser , “ Simulating of RF energy harvesting micro-strip patch antenna over $2.45 \mathrm{GHZ}$ ",International Journal of Engineering \& Technology, 7 (4) (2018) 5484-5488

[5] Rajdevinder Kaur idhu, Jagpal Sing Ubhi, Alpana Aggarwal, "A Survey Study of Different RF Energy Sources for RF Energy Harvesting" International Conference on Automation Computational and Technology Management (ICACTM)

[6] Navpreet Kaur, Nipun Sharma and Naveen Kumar, "RF Energy Harvesting and Storage System of Rectenna" Indian Journal of Science and Technology, Vol 11(25), DOI: 10.17485/ijst/2018/v11i25/114309, July 2018

[7] Sukhveer Kaur, Sushil Kakkar, Shweta Rani, "Design and Analysis of Micro strip Patch Antenna for RF Energy Harvesting", International Journal of Electrical Electronics \& Computer Science Engineering Volume 5, Issue 2 April, 2018

[8] Li Zhu, Jiawei Zhang, Wanyang Han, Leijun Xu, XueBai, "A novel RF energy harvesting cube based on air dielectric antenna arrays", Int J RF Microwave Computer Aided Eng.2018

[9] Mahima Arrawatia, Maryam Shojaei Baghini, and Girish Kumar, "Differential Micro strip Antenna for RF Energy Harvesting" IEEE Transactions on Antennas and Propagation, vol. 63, no. 4, pp.15811588, April 2015

[10] Raj Gaurav Mishra, Ranjan Mishra, Piyush Kucchnal, N.Prasanthi Kumari, " Analysis of the microstrip patch antenna design using genetic algorithm based optimization for wide-band applications "International Journal of Pure and Applied Mathematics Volume 118No.112018,841-849
[11] Raj Gaurav Mishra, Ranjan Mishra, Piyush Kucchnal, N Prasanthi Kumari, "Optimization and analysis of high gain wideband microstrip patch antenna using genetic algorithm " International Journal of Engineering \& Technology, 7 (1.5) (2018) 176-179 